\title{
Serum C-Reactive Protein on the Prognosis of Oncology Patients with Acute Renal Failure: An Observational Cohort Study
}

Jose Ramon Perez Valdivieso, ${ }^{\text {a }}$ Maira Bes-Rastrollo, ${ }^{\text {b }}$ Pablo Monedero, ${ }^{a}$ Luis Lopez Olaondo, ${ }^{a}$ Jokin de Irala, ${ }^{b}$ and Francisco Javier Lavilla ${ }^{\mathrm{c}}$

${ }^{a}$ Department of Anesthesia and Critical Care, Clinica Universitaria, University of Navarra, Pamplona, Spain

${ }^{\mathrm{b}}$ Department of Preventive Medicine and Public Health, University of Navarra, Pamplona, Spain

${ }^{\mathrm{c}}$ Renal Unit, Clinica Universitaria de Navarra, University of Navarra, Pamplona, Spain

\section{BACKGROUND}

We undertook this study to evaluate the significance of the C-reactive protein level (CRP) as a prognostic factor in oncology patients with acute renal failure (ARF) during nephrology consultation.

\section{METHODS}

The study was comprised of a cohort of 375 consecutive oncology patients who had been admitted to a university-affiliated hospital between March 1998 and April 2006 and had been diagnosed with ARF. One hundred and fifty nine patients with ARF who matched at least one of the RIFLE criteria on increased serum creatinine were included for subsequent analysis. We used a Cox proportional hazard model.

\section{RESULTS}

Clinical pathological variables were compared among patients with serum CRP levels $\geq 8 \mathrm{mg} / \mathrm{dL}$ (exposed group; cut-off point: median) and patients with serum CRP level $<8$ $\mathrm{mg} / \mathrm{dL}$ (control group). In-hospital mortality rates associated with CRP levels were $53.8 \%$ for $\geq 8 \mathrm{mg} / \mathrm{dL}$ and $21.5 \%$ for $<8 \mathrm{mg} / \mathrm{dL}(\mathrm{p}<0.001)$. After adjusted analysis, the presence of a CRP level $\geq 8 \mathrm{mg} / \mathrm{dL}$ was significantly associated with an increased inhospital mortality (HR 2.10; 95\% CI: 1.17-3.78) than in those patients with similar Liano scoring, the same RIFLE classes, and the same treatment for ARF. In addition, each increment of $1 \mathrm{mg} / \mathrm{dL}$ of serum CRP was associated with an adjusted $4 \%$ increment of in-hospital mortality (HR 1.04, 95\% CI: 1.01-1.06).

\section{CONCLUSIONS}

CRP levels at nephrology consultation were an independent predictor of death in this cohort of oncology patients with ARF. Patients with levels $\geq 8 \mathrm{mg} / \mathrm{dL}$ may be considered at higher risk of death.

\section{KEY WORDS}

Acute renal failure, C-reactive protein, Liano score, mortality, prognosis, RIFLE.

Address reprint requests to: Jose Ramon Perez Valdivieso, MD, Dept. of Anesthesia and Critical Care and Pain Unit, University Hospital of Navarra, University of Navarra, Avda Pio XII, 36. E-31080 Pamplona, Spain; E-mail: jrpvaldi@unav.es 


\section{INTRODUCTION}

Important advances in the diagnosis and treatment of acute renal failure (ARF) have been made. However, in-hospital mortality rate remains high (1-6). Because of the absence of a consensus definition of ARF, research has been made difficult $(7,8)$. Recently, the Acute Dialysis Quality Initiative (ADQI) published a uniform definition called the RIFLE criteria (Risk, Injury, Failure, Loss, and End-stage) (9), and it has been adopted by the Acute Kidney Injury Network (AKIN) (10).

Severe illness of almost any etiology is accompanied by a generalized host inflammatory response. The single most used and well-studied inflammatory marker is C-reactive protein (CRP) (11-13). It has been well recognized as a prognostic indicator in oncology (14-17), cardiovascular disease $(11,13,18)$, and chronic renal failure $(9-23)$. Nevertheless, information about the risk profile for CRP in ARF is scarce.

Therefore, the objective of this study is to evaluate the impact of serum CRP level at the nephrology consultation on prognosis in oncology patients with ARF.

\section{MATERIALS AND METHODS}

\section{Study Population}

The University Hospital of Navarra is a tertiary care academic teaching medical center with 400 beds in the city of Pamplona, Spain. The hospital ethics committee approved the research project. From March 1998 to April 2006, a cohort of 375 consecutive oncology patients with ARF was prospectively entered into a computerized data-base. We restricted our analysis to patients with adequate increment of creatinine to qualify for the RIFLE criteria for ARF (9) and who were older than 16 years. One hundred and nineteen patients did not fulfill the RIFLE serum creatinine criteria and were not oliguric. Thirteen patients presented oliguria (although it could not be measured on a 6$\mathrm{h}$ basis), but did not fulfill the creatinine criteria. Sixty nine patients had no CRP measured at the time of nephrology consultation. One patient was $<16$ years of age. Fourteen patients did not have complete data recorded. After exclusion, 159 patients remained for subsequent analysis.

\section{Clinical and Laboratory Data}

In this study, ARF was defined as an increase in serum creatinine level sufficient to qualify for the RIFLE criteria.

Serum levels of CRP were measured at the time of nephrology consultation, as part of the routine laboratory samples, by latex photometric immunoassay.

Functional status prior to admission was measured using the Karnofsky Performance Score (24). Patients were classified into the maximum RIFLE class (R, I, or F) according to only their creatinine levels. We were unable to collect full information on urinary output (9). Peak creatinine was defined as the highest creatinine level reached during their admission, using the kinetic Jaffe assay. For patients with no previous history of chronic renal failure, the baseline creatinine was calculated using the Modification of Diet in Renal Disease (MDRD) equation (25), as recommended by the ADQI workgroup (9), assuming a glomerular filtration rate of $75 \mathrm{~mL} / \mathrm{min} / 1.73 \mathrm{~m} 2$ (5). For patients with a history of renal failure, baseline creatinine was defined as the one measured at hospital admission (26). Demographic data, etiology of ARF, comorbid conditions, and laboratory data were all prospectively collected. Severity of illness was measured through Liano score $\left(0.032 *\right.$ age in decades $-0.086^{*}$ male gender - 
$0.109 *$ nephrotoxic $+0.109 *$ oliguria $+0.116 *$ hypotension $+0.122 *$ jaundice + $0.150 *$ coma $-0.154 *$ consciousness $+0.182 *$ assisted respiration +0.210$)(27)$. The difference between serum creatinine value at the time of initial nephrology consultation and baseline value was calculated and expressed in percentage (\%): creatinine change $(\%)=[($ creatinine when nephrologist saw the case — basal creatinine $) /$ basal creatinine $]$ * 100 . We chose to calculate the percentage of the change of creatinine with respect to its baseline because it is modulated by muscle bulk, so even changes as low as 0.3 or $0.5 \mathrm{mg} / \mathrm{dL}$ have distinct significance for patients with different genders and/or ages and whose normal baseline levels are different (7). Food intake was defined as the caloric ingestion during the previous days, and this was classified as appropriate when it was optimal, mild malnutrition when it was inappropriate for $<3$ days, moderate malnutrition when it was inappropriate between 3 and 7 days, and severe malnutrition when it was inappropriate for $>7$ days. The patients' clinical status and treatment for ARF were recorded daily. All cases were treated during admission at our hospital by the same nephrologist, and all data were gathered by the same observer. In our institution, the nephrologist is the only physician who can administer renal replacement therapy according to a strict protocol, so any possible renal replacement therapy had not been started before nephrology consultation.

\section{Analysis}

We focused on relation of CRP and in-hospital mortality. We considered the serum CRP level at the time of nephrology consultation as the exposure variable. Patients were classified into two groups according to their CRP level using the median as cut-off point.

Continuous variables were expressed as medians (and interquartile ranges) and compared using Student's t-test when the variable fitted a normal distribution (evaluated through Kolmogorov-Smirnoff test) or Mann-Whitney $U$ test when it did not. Categorical variables were expressed as proportions and compared with the chi-square test.

Survival time in relation to baseline CRP levels was performed graphically using the Kaplan-Meier survival curve and assessed with the log-rank test.

Cox proportional hazards models were used to determine the independent effect of baseline CRP levels on inhospital mortality. Hazard ratios (HR) and their 95\% confidence intervals (CI) were calculated considering the group of CRP level $<8 \mathrm{mg} / \mathrm{dL}$ as the reference category. Additionally, we considered baseline CRP levels as a continuous variable, calculating the HR associated with $1 \mathrm{mg} / \mathrm{dl} \mathrm{CRP}$ increment. We fitted a crude model (univariate, i.e., without any adjustment) and a multivariateadjusted model including all those variables found statistically significant in the descriptive analysis plus age and sex. Furthermore, we present a table including the crude and adjusted associations of those variables that remained significant in the multivariate model: CRP levels, Liano scoring, and Karnofsky scoring, plus age and sex. Liano scoring includes in its equation the variables for nephrotoxicity, oliguria, hypotension, jaundice, mental status, and assisted respiration.

Examination of proportionality assumptions in the Cox model indicated no significant time $\mathrm{x}$ risk factor interactions for any variable in the model.

We analyzed overall survival at 60 days across groups using the Kaplan-Meier methods and tested differences between groups using the log-rank test. The time of origin was the day when the nephrology consultation began. The event defined was death, whereas those cases alive at the end of follow-up and those lost to follow-up were censored at their last observation. 
All $p$ values presented are two tailed; $p<0.05$ was considered statistically significant. Statistical analyses were conducted using SPSS v.10.0.7 (SPSS Inc., Chicago, IL).

\section{RESULTS}

More than one third of the patients with CRP levels $<8 \mathrm{mg} / \mathrm{dL}$ had kidney cancer, whereas patients in the $\geq 8 \mathrm{mg} / \mathrm{dL}$ group presented no predominant type of malignancy (Table 1). Demographic and clinical characteristics for the 159 patients are shown in Table 2. Overall mean level of CRP was $11.56 \mathrm{mg} / \mathrm{dL}$ (SD 11.59). The mortality rate was significantly higher in the group with $\geq 8 \mathrm{mg} / \mathrm{dL}$ (median as a cut-off). Among the patients with $\geq 8 \mathrm{mg} / \mathrm{dL}, 43$ died $(53.8 \%)$ compared to $17(21.5 \%)$ in the $<8 \mathrm{mg} / \mathrm{dL}$ group ( $\mathrm{p}<0.001)$. There were important baseline differences between both groups that may be associated with survival. Serum levels of CPR $\geq 8 \mathrm{mg} / \mathrm{dL}$ were associated with higher increments of serum creatinine level with respect to baseline and lower levels of serum albumin. Serum levels of $\geq 8 \mathrm{mg} / \mathrm{dL}$ were also associated with poorer Liano and Karnofsky scorings and more severe RIFLE categories. Prior nutrition intake was impaired in patients with CRP levels $\geq 8 \mathrm{mg} / \mathrm{dL}$, and they needed dialysis treatments more often. There were no differences in terms of mortality in connection with outpatient ARF or hemoglobin levels. Mean hemoglobin level for survivors was 11.17 $\mathrm{mg} / \mathrm{dL}$ (95\% CI: 10.73-11.61) and was $10.64 \mathrm{mg} / \mathrm{dL}$ (95\% CI: 10.14-11.14) for nonsurvivors. After adjusting for age, sex, Liano scoring, Karnofsky score, nutrition intake, RIFLE classes, treatment of ARF, relative increment of serum creatinine, and serum albumin with multivariate Cox proportional hazard model, a serum CRP level $\geq 8 \mathrm{mg} / \mathrm{dL}$ was an independent and significant in-hospital mortality predictor [hazard ratio (HR) $2.10,95 \% \mathrm{CI}: 1.10-4.01], \mathrm{p}=0.025$. For each $1 \mathrm{mg} / \mathrm{dL}$ increase, the risk ratio of mortality was 4\% higher (HR 1.04, 95\% CI: 1.01-1.06), $\mathrm{p}=0.014$.

When we adjusted only for age, sex, Liano and Karnofsky scorings, HR was similar (Table 3). Furthermore, the association between mortality and higher Liano scorings and lower Karnofsky scores was clear, as shown in the related HRs. However, neither age nor sex seemed to have influence on the HR for in-hospital mortality.

We analyzed short-term survival. According to the Kaplan-Meier plot, CRP levels $\geq 8$ $\mathrm{mg} / \mathrm{dL}$ also presented a statistically significant higher mortality rate in the period between the nephrology consultation and 60 days (Figure 1) compared to CRP levels $<8$ $\mathrm{mg} / \mathrm{dL}(\log$ rank test $=18.05 ; \mathrm{p}<0.001)$. Most of the deaths (39 and 17 deaths for CRP levels $\geq 8 \mathrm{mg} / \mathrm{dL}$ and $<8 \mathrm{mg} / \mathrm{dL}$, respectively) occurred during the first 60 days of follow-up.

\section{DISCUSSION}

This study involved oncology patients with ARF and sought to identify if CRP levels were a predictor of mortality. Our results are consistent with several established studies $(12-23,28,29)$ but never previously among oncology patients with ARF. CRP was associated with higher mortality after adjusting for possible confounders. Patients with the same Liano scoring and RIFLE classes and who received the same treatment for ARF had different mortality rates according to the CRP level at the time of nephrology consultation. This may suggest that inflammation plays a role in the outcome of oncology patients with ARF. On the other hand, serum CRP level was correlated with poor prognosis in oncology patients per se in other studies $(12,14,16,17,28,29)$, 
although its mechanism is not well understood yet. In addition, CRP is known to increase with declining kidney function (19,30-32). A high value ( $\geq 8 \mathrm{mg} / \mathrm{dL}) \mathrm{might}$ indicate an unfavorable health condition. Measuring serum CRP at the beginning of nephrology consultation may help in selecting patients who would benefit or not from intensive therapy. The hazard ratio for mortality of 2.10 in patients with CRP $\geq 8 \mathrm{mg} / \mathrm{dL}$ may show the importance of inflammation on outcome. It may be another use for a widely available, standardized, reliable and relatively inexpensive inflammation marker (13).

It was important to adjust for the severity of illness due to the heterogeneous nature of ARF (3). The Liano score was chosen because of its ability to delineate mortality from survival and also for its ability to calibrate the observed mortality rate with the expected mortality in ARF $(3,6,33)$. It was also important to adjust for the severity of the ARF. The RIFLE consensus criteria gives a standard definition and a level of classification of severity in ARF (9), a request often made by the experts $(7,8)$. Adjusting for the severity of comorbid illnesses and using the RIFLE criteria may allow compare further investigation in ARF.

Chronic renal failure was included in this study to represent the common clinical practice. The proportion of patients was similar between groups.

It is also interesting to determine the risk of death per each $1 \mathrm{mg} / \mathrm{dL}$ of serum CRP because this kind of measurement may be useful to improve the knowledge of the risk profile of every patient. Due to the observational nature of the present study, no conclusions can be made with confidence, but it should encourage future research on understanding the influence of CRP levels on mortality in ARF and/or oncology patients.

There are several limitations to this study. The sample size was small and may limit the analysis. Therefore, large confidence intervals were found. It could be argued that the study took place in a single hospital with its limits to apply to other centers. Urine output data were not available; therefore, it was not possible to estimate the RIFLE criteria according to this value. We began to collect data before the RIFLE criteria were formulated, and most of the ward patients had no urinary output measured on a 6-h basis. We assume that we might underestimate some cases according to the RIFLE criteria and exclude others (although only 13 patients were excluded). At the same time, serum baseline creatinine values were calculated by the MDRD equation, on an assumed glomerular filtration rate (GFR) of $75 \mathrm{~mL} / \mathrm{min} / 1.73 \mathrm{~m}^{2}$ (5). This formula has been shown to underestimate the GFR in healthy subjects and even more in ill patients (34) because it was derived from patients with chronic renal failure $(35,36)$, and it may therefore underestimate the severity of ARF when using the RIFLE criteria (37). This lack of reliability remains one of the controversial issues regarding the RIFLE criteria and needs further clarification (38).

The possibility of residual confounding cannot be ruled out, but it is unlikely that it can fully explain the observed strong associations. We cannot precisely establish serum CRP level that may be clinically relevant because the decision to take the cut-off point of $8 \mathrm{mg} / \mathrm{dL}$ was done mathematically.

In conclusion, CRP level at the time of nephrology consultation was associated with a significant increase in the risk of death in this cohort of oncology patients with ARF.

\section{ACKNOWLEDGMENTS}

The authors wish to express their gratitude for the contributions made by Dr. Zubair Kabir. 


\section{REFERENCES}

1. Abosaif NY, Tolba YA, Heap M, Russell J, El Nahas AM. The outcome of acute renal failure in the intensive care unit according to RIFLE: model application, sensitivity, and predictability. Am J Kidney Dis 2005;46:10381048.

2. Herrera-Gutierrez ME, Seller-Perez G, Maynar-Moliner J, Sanchez-IzquierdoRiera JA. Epidemiology of acute kidney failure in Spanish ICU. Multicenter prospective study FRAMI. Med Intensiva 2006;30: 260-267.

3. Star RA. Treatment of acute renal failure. Kidney Int 1998;54: 1817-1831.

4. Uchino S. The epidemiology of acute renal failure in the world. Curr Opin Crit Care 2006;12:538-543.

5. Uchino S, Bellomo R, Goldsmith D, Bates S, Ronco C. An assessment of the RIFLE criteria for acute renal failure in hospitalized patients. Crit Care Med 2006;34:1913-1917.

6. Uchino S, Bellomo R, Morimatsu H, Morgera S, Schetz M, Tan I, et al. External validation of severity scoring systems for acute renal failure using a multinational database. Crit Care Med 2005;33:1961-1967.

7. Bellomo R, Kellum J, Ronco C. Acute renal failure: time for consensus. Intensive Care Med 2001;27:1685-1688.

8. Kellum JA, Levin N, Bouman C, Lameire N. Developing a consensus classification system for acute renal failure. Curr Opin Crit Care 2002; 8:509514.

9. Bellomo R, Ronco C, Kellum JA, Mehta RL, Palevsky P. Acute renal failure-definition, outcome measures, animal models, fluid therapy and information technology needs: the Second International Consensus Conference of the Acute Dialysis Quality Initiative (ADQI) Group. Crit Care 2004;8:R204-R212.

10. Bellomo R, Kellum JA, Ronco C. Defining and classifying acute renal failure: from advocacy to consensus and validation of the RIFLE criteria. Intensive Care Med 2007;33:409-413.

11. Pepys MB, Hirschfield GM. C-reactive protein: a critical update. J Clin Invest 2003;111:1805-1812.

12. de Mello J, Struthers L, Turner R, Cooper EH, Giles GR. Multivariate analyses as aids to diagnosis and assessment of prognosis in gastrointestinal cancer. Br J Cancer 1983;48:341-348.

13. Pearson TA, Mensah GA, Alexander RW, Anderson JL, Cannon RO 3rd, Criqui $\mathrm{M}$, et al. Markers of inflammation and cardiovascular disease: application to clinical and public health practice: a statement for healthcare professionals from the Centers for Disease Control and Prevention and the American Heart Association. Circulation 2003;107:499-511.

14. Hashimoto K, Ikeda Y, Korenaga D, Tanoue K, Hamatake M, Kawasaki K, et al. The impact of preoperative serum C-reactive protein on the prognosis of patients with hepatocellular carcinoma. Cancer 2005;103:1856-1864.

15. Ikeda M, Natsugoe S, Ueno S, Baba M, Aikou T. Significant host- and tumorrelated factors for predicting prognosis in patients with esophageal carcinoma. Ann Surg 2003;238:197-202.

16. Nakanishi H, Araki N, Kudawara I, Kuratsu S, Matsumine A, Mano M, et al. Clinical implications of serum C-reactive protein levels in malignant fibrous histiocytoma. Int J Cancer 2002;99:167-170. 
17. Terpos E, Szydlo R, Apperley JF, Hatjiharissi E, Politou M, Meletis J, et al. Soluble receptor activator of nuclear factor kappaB ligandosteoprotegerin ratio predicts survival in multiple myeloma: proposal for a novel prognostic index. Blood 2003;102:1064-1069.

18. Ross R. Atherosclerosis - an inflammatory disease. $\mathrm{N}$ Engl J Med 1999;340:115-126.

19. Lacson E Jr, Levin NW. C-reactive protein and end-stage renal disease. Semin Dial 2004;17:438-448.

20. Menon V, Greene T, Wang X, Pereira AA, Marcovina SM, Beck GJ, et al. Creactive protein and albumin as predictors of all-cause and cardiovascular mortality in chronic kidney disease. Kidney Int 2005;68:766-772.

21. Stenvinkel P, Lindholm B. C-reactive protein in end-stage renal disease: are there reasons to measure it? Blood Purif 2005;23:72-78.

22. Tsirpanlis G. The pattern of inflammation and a potential new clinical meaning and usefulness of C-reactive protein in end-stage renal failure patients. Kidney Blood Press Res 2005;28:55-61.

23. van der Sande FM, Kooman JP, Leunissen KM. The predictive value of Creactive protein in end-stage renal disease: is it clinically significant? Blood Purif 2006;24:335-341.

24. Karnofsky DA, Burchenal JH, eds. The Clinical Evaluation of Chemotherapeutic Agents in Cancer. New York: Columbia University Press; 1949.

25. National Kidney Foundation. K/DOQI clinical practice guidelines for chronic kidney disease: evaluation, classification, and stratification. Am J Kidney Dis 2002;39(2 Suppl. 1):S1-S266.

26. Hoste EA, Clermont G, Kersten A, Venkataraman R, Angus DC, De Bacquer $\mathrm{D}$, et al. RIFLE criteria for acute kidney injury are associated with hospital mortality in critically ill patients: a cohort analysis. Crit Care 2006;10:R73.

27. Liano F, Gallego A, Pascual J, Garcia-Martin F, Teruel JL, Marcen R, et al. Prognosis of acute tubular necrosis: an extended prospectively contrasted study. Nephron 1993;63:21-31.

28. McMillan DC, Canna K, McArdle CS. Systemic inflammatory response predicts survival following curative resection of colorectal cancer. Br J Surg 2003;90:215-219.

29. Nozoe T, Matsumata T, Kitamura M, Sugimachi K. Significance of preoperative elevation of serum C-reactive protein as an indicator for prognosis in colorectal cancer. Am J Surg 1998;176:335-338.

30. Kaysen GA. The microinflammatory state in uremia: causes and potential consequences. J Am Soc Nephrol 2001;12:1549-1557.

31. Shlipak MG, Fried LF, Crump C, Bleyer AJ, Manolio TA, Tracy RP, et al. Elevations of inflammatory and procoagulant biomarkers in elderly persons with renal insufficiency. Circulation 2003;107:87-92.

32. Stuveling EM, Hillege HL, Bakker SJ, Gans RO, De Jong PE, De Zeeuw D. C-reactive protein is associated with renal function abnormalities in a nondiabetic population. Kidney Int 2003;63: 654-661.

33. Douma CE, Redekop WK, van der Meulen JH, van Olden RW, Haeck J, Struijk DG, et al. Predicting mortality in intensive care patients with acute renal failure treated with dialysis. J Am Soc Nephrol 1997;8:111-117.

34. Poggio ED, Nef PC, Wang X, Greene T, Van Lente F, Dennis VW, et al. Performance of the Cockcroft-Gault and modification of diet in renal disease 
equations in estimating GFR in ill hospitalized patients. Am J Kidney Dis 2005;46:242-252.

35. Poggio ED, Wang X, Greene T, Van Lente F, Hall PM. Performance of the modification of diet in renal disease and Cockcroft-Gault equations in the estimation of GFR in health and in chronic kidney disease. J Am Soc Nephrol 2005;16:459-466.

36. Rule AD, Larson TS, Bergstralh EJ, Slezak JM, Jacobsen SJ, Cosio FG. Using serum creatinine to estimate glomerular filtration rate: accuracy in good health and in chronic kidney disease. Ann Intern Med 2004;141:929-937.

37. Maccariello E, Soares M, Valente C, Nogueira L, Valenca RV, Machado JE, et al. RIFLE classification in patients with acute kidney injury in need of renal replacement therapy. Intensive Care Med 2007; 33:597-605.

38. Joannidis M. Classification of acute kidney injury: are we there yet? Intensive Care Med 2007;33:572-574. 


\begin{tabular}{|c|c|c|}
\hline Malignancy & $\mathrm{CRP}<8 \mathrm{mg} / \mathrm{dL}$ & $C R P \geq 8 \mathrm{mg} / \mathrm{dL}$ \\
\hline Kidney cancer & 38.0 & 10.0 \\
\hline Breast cancer & 12.7 & 8.8 \\
\hline Colorectal cancer & 11.4 & 13.8 \\
\hline Endometrial cancer & 6.3 & 10.0 \\
\hline Skin cancer & 5.1 & 6.3 \\
\hline Lung cancer & 3.8 & 10.0 \\
\hline Hepatocellular cancer & 3.8 & 1.3 \\
\hline Pancreatic cancer & 3.8 & 6.3 \\
\hline Hematological & 2.5 & 3.8 \\
\hline Bladder cancer & 1.3 & 5.0 \\
\hline Stomach cancer & 1.3 & 6.3 \\
\hline Prostate cancer & 1.3 & 2.7 \\
\hline Undetermined & 2.5 & 1.3 \\
\hline Miscellaneous & 6.2 & 14.4 \\
\hline
\end{tabular}


Table 2. Characteristics of patients according to C-reactive protein (CRP) level

\begin{tabular}{|c|c|c|c|}
\hline Variables* & $\begin{array}{c}\mathrm{CRP}<8 \mathrm{mg} / \mathrm{dL} \\
\mathrm{n}=79\end{array}$ & $\begin{array}{c}C R P \geq 8 \mathrm{mg} / \mathrm{dL} \\
\mathrm{n}=80\end{array}$ & $\begin{array}{c}\mathbf{P}^{\sim} \\
\text { value }\end{array}$ \\
\hline Increase of creatinine $^{\#}$ : median $\%$ (IQR) & $62.74(147.66)$ & $118.00(235.11)$ & 0.013 \\
\hline Age: median years (IQR) & $56.10(11.95)$ & $56.16(11.83)$ & 0.97 \\
\hline Sex: male $(\%)$ & 58.2 & 62.5 & 0.63 \\
\hline $\begin{array}{l}\text { Patients with no previous history of chronic renal } \\
\text { failure }(\%)\end{array}$ & 79.7 & 82.5 & 0.69 \\
\hline $\begin{array}{l}\text { Basal serum creatinine (mg/dL) according to the } \\
\text { MDRD equation: median (IQR) }\end{array}$ & $1.03(0.22)$ & $1.04(0.23)$ & 0.63 \\
\hline Patients with history of chronic renal failure (\%) & 20.3 & 17.5 & 0.69 \\
\hline Basal serum creatinine (mg/dL): median (IQR) & $1.20(1.00)$ & $1.30(1.25)$ & 0.16 \\
\hline RIFLE criteria $(\%)$ & & & 0.02 \\
\hline Risk & 30.4 & 21.2 & \\
\hline Injury & 31.6 & 18.8 & \\
\hline Failure & 38.0 & 60.0 & \\
\hline Basal serum albumin (g/dL): median (IQR) & $2.88(0.73)$ & $2.19(0.60)$ & $<0.001$ \\
\hline Basal hemoglobin (g/dL): median (IQR) & $11.36(1.92)$ & $10.59(2.23)$ & 0.022 \\
\hline Community-acquired acute renal failure (\%) & 30.8 & 45.8 & 0.15 \\
\hline Liano scoring: median score (IQR) & $0.17(0.21)$ & $0.25(0.30)$ & 0.03 \\
\hline Karnofsky scoring: median score (IQR) & $73.65(15.27)$ & $63.09(12.49)$ & $<0.001$ \\
\hline Hypotension (\%) & 30.4 & 42.5 & 0.139 \\
\hline Oliguria (\%) & 24.1 & 43.8 & 0.012 \\
\hline Jaundice $(\%)$ & 17.7 & 31.3 & 0.065 \\
\hline Coma $(\%)$ & 7.6 & 11.3 & 0.589 \\
\hline Consciousness $(\%)$ & 81.0 & 85.0 & 0.533 \\
\hline Mechanical ventilation (\%) & 12.7 & 16.3 & 0.653 \\
\hline Aminoglycoside use (\%) & 16.5 & 22.5 & 0.42 \\
\hline Radiocontrast procedures $(\%)$ & 17.7 & 22.5 & 0.55 \\
\hline Diabetic $(\%)$ & 2.5 & 2.5 & 1.00 \\
\hline Nephrotoxicity (\%) & 65.8 & 58.8 & 0.41 \\
\hline Causes of acute renal failure & & & 0.46 \\
\hline Pre-renal (\%) & 78.5 & 78.2 & \\
\hline Intrinsic renal $(\%)$ & 15.2 & 8.8 & \\
\hline Post-renal (\%) & 2.5 & 1.2 & \\
\hline Other causes $(\%)$ & 3.8 & 8.8 & \\
\hline Treatment of acute renal failure & & & 0.016 \\
\hline Non-dialysis (\%) & 84.8 & 66.3 & \\
\hline Intermittent hemodialysis $(\%)$ & 1.3 & 11.3 & \\
\hline Continuous replacement therapy (\%) & 8.9 & 17.5 & \\
\hline Both (intermittent $\mathrm{p}$ continuous) (\%) & 5.1 & 5.0 & \\
\hline Nutrition intake & & & $<0.001$ \\
\hline Optimal nutrition $(\%)$ & 41.2 & 13.2 & \\
\hline Mild malnutrition $(\%)$ & 14.7 & 13.2 & \\
\hline Moderate malnutrition (\%) & 32.4 & 22.1 & \\
\hline Severe malnutrition (\%) & 11.8 & 51.5 & \\
\hline
\end{tabular}

IQR, interquartile range; MDRD, modification of diet in renal disease.

*Continuous variables are expressed as median and interquartile range.

$\sim \mathrm{p}$ value was tested by Pearson chi square test for categorical variables and MannWhitney U test for continuous variables.

\# Creatinine increase $(\%)=[($ creatinine when nephrologist saw the case e basal creatinine $) /$ basal creatinine $] * 100$. 
Table 3. Hazard ratios (HRs) and 95\% confidence intervals of in-hospital mortality for different serum C-reactive protein levels and other factors

\begin{tabular}{|l|c|c|c|c|}
\hline & $\begin{array}{c}\text { Crude HR } \\
(\mathbf{9 5 \%} \text { CI) }\end{array}$ & p value & $\begin{array}{c}\text { Multivariate* } \\
\text { HR (95\% CI) }\end{array}$ & p value \\
\hline C-reactive protein $\geq 8 \mathrm{mg} / \mathrm{dL}$ & $3.09(1.78-5.37)$ & $<0.001$ & $2.10(1.17-3.78)$ & 0.013 \\
\hline Liano scoring & & & & \\
\hline $1(0.16)$ & 1 (Reference) & & 1 (Reference) & \\
\hline $2(0.28)$ & $2.07(1.01-4.23)$ & 0.040 & $1.54(0.73-3.25)$ & 0.260 \\
\hline $3(0.62)$ & $13.78(7.18-26.45)$ & $<0.001$ & $8.23(4.15-16.33)$ & $<0.001$ \\
\hline Karnofsky scoring ${ }^{\#}$ & & & & \\
\hline $1(50)$ & $1($ Reference) & & $1($ Reference) & \\
\hline $2(60)$ & $0.39(0.20-0.75)$ & 0.005 & $0.56(0.28-1.12)$ & 0.09 \\
\hline $3(90)$ & $0.05(0.02-0.18)$ & $<0.001$ & $0.14(0.04-0.55)$ & 0.004 \\
\hline Age (for every year older) & $1.02(0.99-1.04)$ & 0.08 & $1.01(0.99-1.03)$ & 0.31 \\
\hline Sex (male) & $0.97(0.58-1.61)$ & 0.90 & $0.92(0.53-1.61)$ & 0.78 \\
\hline $\begin{array}{l}\text { *Adjusted for all the variables included in the table. } \\
\text { \#Expressed as tertiles and (median). }\end{array}$ \\
\hline
\end{tabular}




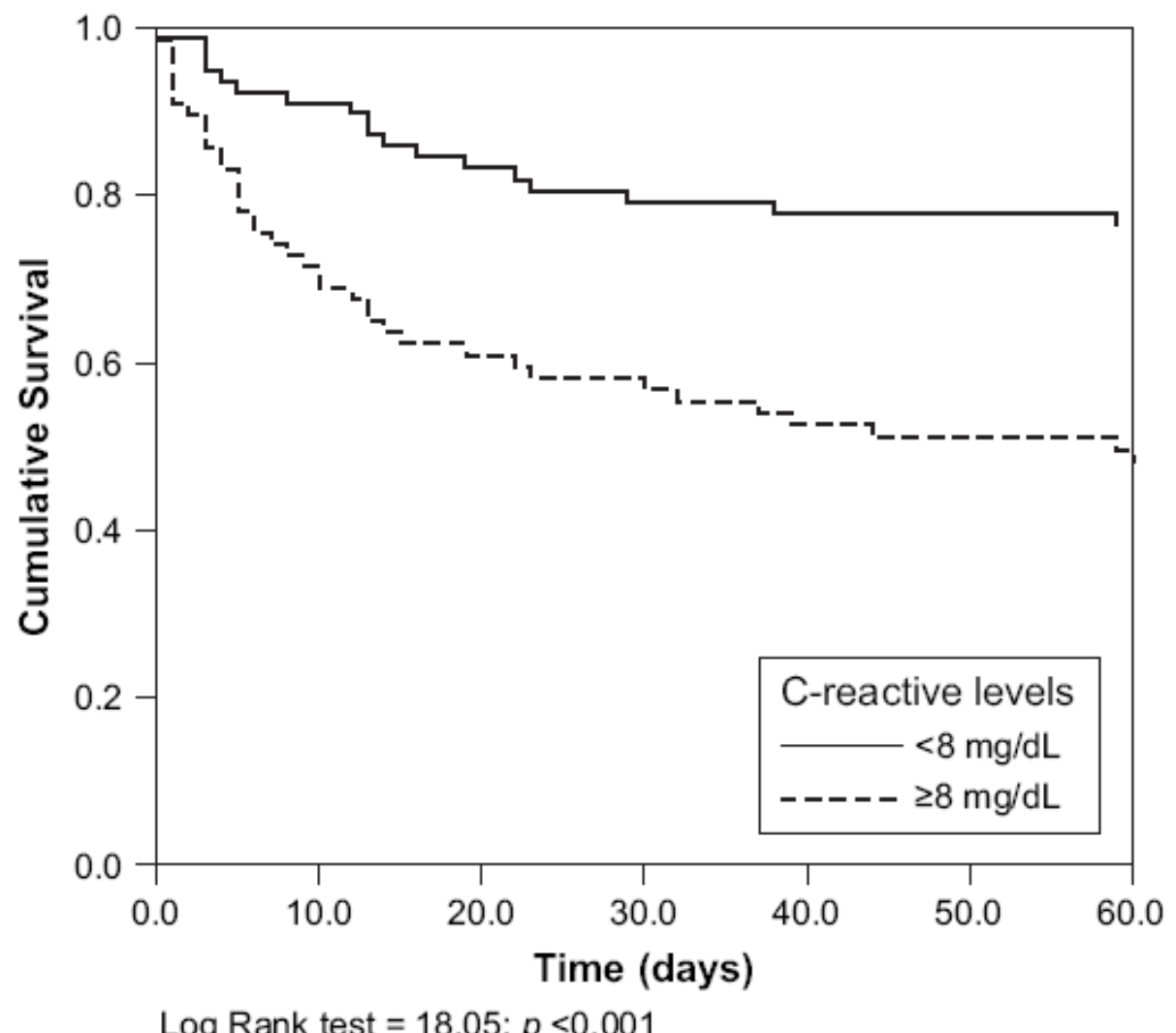

Figure 1. Cumulative survival. 